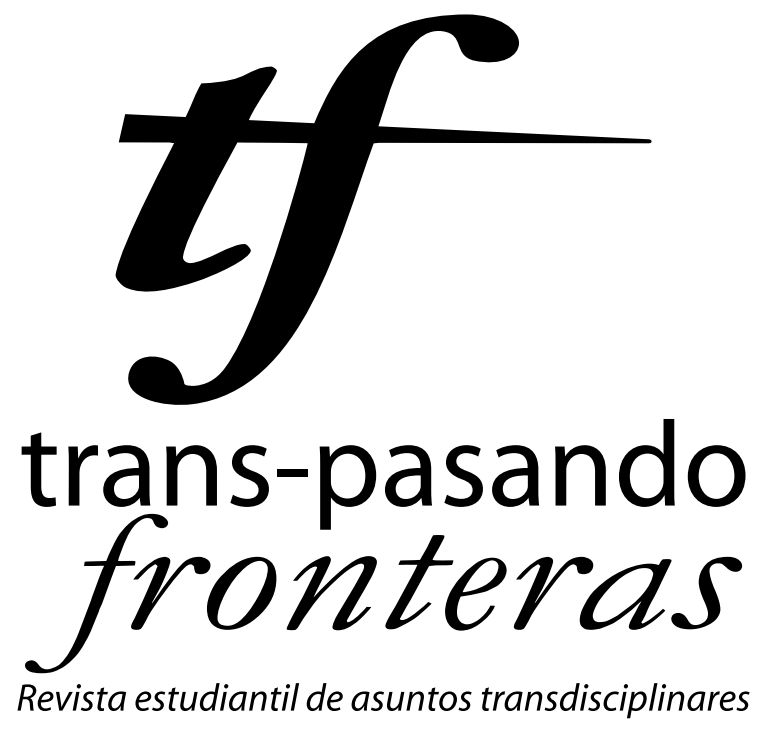

Una publicación de

Estudios

Interdisciplinarios

Jurídicos, Sociales

000 y Humanistas

ICESS

FACULTAD DE

DERECHO Y CIENCIAS

SOCIALES

然 UNIVERSIDAD 


\title{
Una alianza en temas seguridad entre México y Estados Unidos
}

\author{
Lina María Mejía
(linita.mejia@hotmail.com) \\ Lina María Mejía
(linita.mejia@hotmail.com)
}

\author{
Estefanía Aristizabal \\ (tefi662@hotmail.com)
}

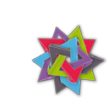

VELÁZQUeZ FlORES, Rafael y Juan Pablo Prado Lallande (coords.) (2009). La Iniciativa Mérida: ¿nuevo paradigma de cooperaciónentre México y Estados Unidos en seguridad?. México: Benemérita Universidad Autónoma de Puebla/Universidad Nacional Autónoma de México. 441 pp.

El licenciado y maestro Rafael Velázquez Flores, y el profesor investigador Juan Pablo Prado Lallande de la Universidad de Puebla, México, ambos coordinadores del proyecto Iniciativa Mérida la cual consiste en una alianza entre Estados Unidos y México en la lucha contra el narcotráfico, nos presentan en el 2012 un completo compilado de trabajos que explican desde diferentes perspectivas como este pacto permea diferentes escenarios en materia de seguridad en los Estados Unidos y México. Estas diferentes perspectivas giran alrededor de un postulado central, en el cual explican que el proyecto Mérida ha sido un acuerdo poco claro en cuanto a jurisdicción, objetivos, rendición de cuentas e instituciones involucradas en estos dos países.

$\mathrm{Al}$ inicio del texto La Iniciativa Mérida: ¿nuevo paradigma de cooperaciónentre México y Estados Unidos en seguridad?, los coordinadores del proyecto reconocen la inminente amenaza en la que se ve el Estado mexicano frente a los espacios de poder que están siendo ocupados por un gran número de células de narcotraficantes que realizan sus actividades ilícitas a lo largo y ancho de la nación. Razón por la cual la legitimidad del gobierno y su eficiencia al proceder en las políticas públicas, ha sido fuertemen- 
te cuestionada, además de la corrupción reinante. Instituciones del Estado mexicano dedicadas a combatir el narcotráfico se revelan débiles y vulnerables ante el poder de los carteles.

Desde la portada del libro los autores exponen una pregunta crucial que muestra la importancia y prioridad de la seguridad en la relación entre México y Estados Unidos. Los compiladores, en los 15 capítulos, dejan en manifiesto que la Iniciativa Mérida no puede ser considerada como un nuevo paradigma de cooperación entre ambos Estados, ya que estos dos países han establecido alianzas significativas en estos temas con anterioridad.

En relación al contenido de la obra, existen grandes fragmentos que presentan diferentes periodizaciones en cuanto a la iniciación de los procesos de cooperación en materia de seguridad entre estas dos naciones. Algunos sitúan el punto de partida en 1848 con el Tratado GuadalupeHidalgo, otros lo ubican desde la Segunda Guerra Mundial; y por último, un gran número le apuesta a que ésta empezó en la década de 1980, cuando se incrementó paralelamente la demanda de drogas en Estados Unidos y la producción en el Sur del continente.

Para desarrollar el postulado ante- riormente expuesto, el libro posee una estratégica división del contenido. Cada compilador argumenta desde distintos enfoques teóricos y diversas fuentes de información. En este sentido, al reunir múltiples matices que contestan a una misma pregunta, se logran obtener diferentes interpretaciones y aplicaciones teóricas de esa problemática social. Por lo tanto, esta puede ser una invitación para abordar esta problemática desde una perspectiva transdisciplinar. Por otro lado, el lector entra a conocer un poco más afondo el esquema de análisis regional $^{1}$. Finalmente, explica la cooperación en materia de seguridad usando como ejemplo la Iniciativa Mérida, a la que le aplican los postulados de las diversas teorías de las Relaciones Internacionales de una forma clara e ilustrativa.

El libro resalta la visibilidad real de los actores que participan en el diseño y en la negociación del proyecto de cooperación, lo cual es una cuestión de mucha importancia para explicar los mecanismos utilizados por los tecnócratas para la toma de decisiones en el contexto de la lucha contra el narcotráfico. Consideramos que este punto es crucial ya que en

1 Para ello se explica desde el plano norteamericano y también desde el plano mexicano. 
muchas ocasiones solo se muestran las caras populares, por llamarlo de alguna manera, mas no las caras reales las cuales realizan los diálogos bilaterales y organizacionales del pacto.

Es oportuno hablar a groso modo de los elementos más importantes que contiene esta obra. En la primera parte, se emprende la Iniciativa Mérida desde la visión de México, resaltando el papel central de distintos sectores del gobierno como el Poder Legislativo, algunos líderes de opinión y las fuerzas militares mexicanas. No obstante, esta sección detalla con más claridad el contenido de la alianza y de qué manera se repartirán los fondos destinados a la financiación de este proyecto. Además, los autores coinciden en la idea de que la Iniciativa, contiene estrategias sólidas para un fortalecimiento del sistema institucional mexicano ${ }^{2}$.

La segunda parte está compuesta por una explicación de la Iniciativa Mérida desde la visión de los Estados Unidos, en tanto al cambio radical de la importancia en materia de seguridad ya que logra convertirse en el tema prioritario de la agen-

2 Este punto es crucial ya que como expreso en la parte superior muchas de estas instituciones se han visto vulneradas por el poder criminal de las células narcotraficantes. da en la relación con México después del 2001. En esta misma línea, los escritores abren también el debate acerca del el desempeño del Congreso estadounidense y exponen una cronología en la que se detalla todo el proceso de cooperación, desde su inicio hasta que el Congreso estadounidense aprobó el monto final de 470 millones de dólares.

En la tercera sección se examina la Iniciativa Mérida desde la perspectiva de la cooperación internacional. Se muestran argumentos sobre la necesidad de enfocar los esfuerzos en la seguridad humana, (la seguridad de la ciudadanía mexicana y norteamericana), y la directa relación de estos con las decisiones tomadas en el pacto.

Por último, la cuarta sección presenta perspectivas regionales sobre su diseño e impacto. Es crucial el abordaje de este última sección ya que los autores explican un poco mejor cuales son los demás países asociados a este pacto que recibirán regalías y ayuda estratégica por parte de Estados Unidos para el combate contra el narcotráfico. En esta parte hacen referencia a la importancia del Plan Colombia como un punto clave en la estrategia de seguridad estadounidense en la zona.

Lo cierto es que la desarrollo del li- 
bro resulta interesante, ya que nos hace preguntarnos si es pertinente contar con la participación ciudadana y del poder legislativo en el tema del narcotráfico, que representa un interés nacional e internacional. Teniendo en cuenta que a nivel constitucional, en el Estado de México y en los Estados Unidos, dicho asunto son de facultad exclusiva de la rama ejecutiva.

Otro punto importante a señalar es que no cabe duda alguna que es necesario, redefinir los conceptos de seguridad y amenaza en ambos países para que así puedan ser adecuarlos a un contexto de globalización e integración regional.

Antes de finalizar esta reseña, es importante que quede claro que el libro concluye que la Iniciativa Mérida se presenta como un acto de cooperación figurada, pues la estimación de recursos no son lo suficientemente significativos por cuestiones del alto grado de corrupción.

En conclusión, recomendamos el libro a aquellas personas que no le temen al debate conceptual entre las diferentes teorías de las Relaciones Internacionales enfocadas en la lucha contra el narcotráfico, lo que representa uno de los retos pendientes del anterior milenio. Por último quisiéramos dejarles la siguiente cuestión a considerar ¿Es la Iniciativa Mérida un acto simbólico o una verdadera estrategia en la lucha contra el narcotráfico? 